\title{
Food for Thought?
}

\section{Lisa Fine and Stan Wagon}

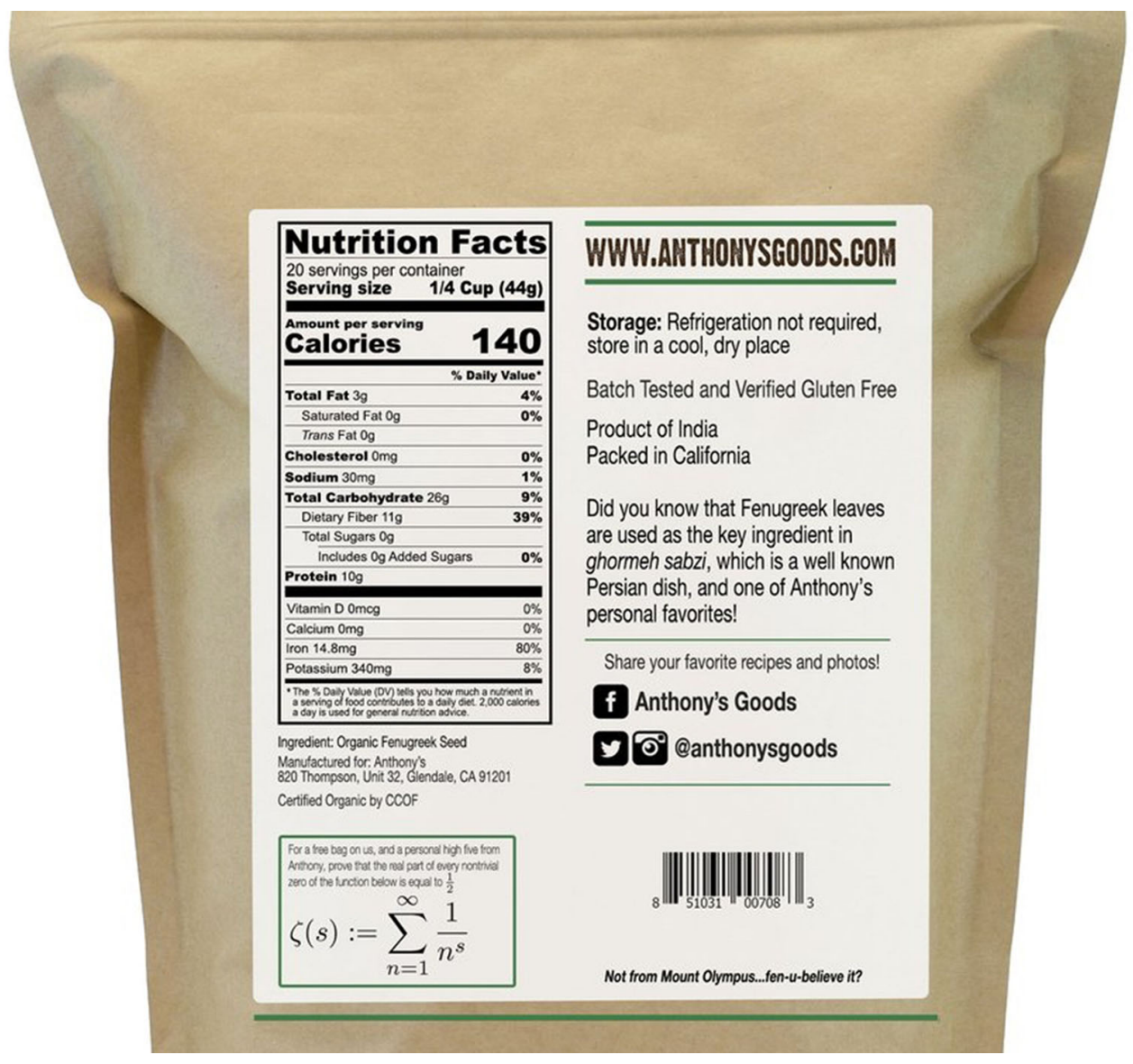

Great news for mathematicians! For solving the Riemann hypothesis you will receive, in addition to the million dollar prize offered by the Clay Mathematics Institute, a free bag of fenugreek seeds from Anthony's Goods. You will note, however, if you read the fine print, that if you resolve the Riemann hypothesis in the negative, you will not get the bag of seeds (although you will receive the million dollars). (Image courtesy of Anthony's Goods.)

Lisa Fine

Silverthorne, CO, USA

e-mail: lisafine@flexotech.net

\author{
Stan Wagon \\ Macalester College \\ St. Paul, Minnesota, USA \\ e-mail: wagon@macalester.edu
}

Publisher's Note Springer Nature remains neutral with regard to jurisdictional claims in published maps and institutional affiliations. 